\title{
Leadership, Coaching and Emotional Intelligence of the Leader - Possible Relations, Dissonances and Realizations
}

\author{
Assoc. Prof. Velislava Nikolaeva, PhD \\ Varna Free University "Chernorizets Hrabar”, Varna, Bulgaria \\ velislava.nikolaeva@vfu.bg
}

\begin{abstract}
To change the conditions for doing business requires a change in the behavior of those who run the organization. The paper accepts the statement that the leaders must meet the notion for managers-leaders. The article's focus is on the set of specific knowledge, skills and competencies that they must have, in order to be successful and effective in relation to the current requirements of the business management environment. Subject of research is the integration between the qualities and skills of a successful manager, the requirements for emotional intelligence of the leader, and coaching as a management tool to influence the behavior of managers and employees. The defended author's thesis is that managers developing their professional abilities, should learn various tools to apply in their management practice, as well as to apply techniques for managing emotional intelligence. Coaching is considered such an instrument.
\end{abstract}

Keywords: leadership, coaching, emotional intelligence, management.

JEL Code: M10 DOI: https://doi.org/10.36997/IJUSV-ESS/2020.9.1.137

Въведение

Промяната в условията за правене на бизнес изисква промяна в поведението на тези, които ръководят организацията. В разработката се възприема твърдението, че тези ръководители трябва да отговарят на разбирането за мениджъри-лидери. Фокусът в статията е поставен върху съвкупността от специфични знания, умения и компетенции, които те трябва да притежават, за да бъдат успешни и резултатни по отношение на актуалните изисквания на средата за управление на бизнеса. Предмет на изследване е интеграцията между качествата и уменията на успешния мениджър, изискванията за емоционална интелигентност на лидера и коучинга като управленски инструмент за въздействие върху поведението на ръководителите и служителите. Защитаваната авторова теза е, че мениджърите, развивайки своите професионални способности следва да усвояват различни инструменти, които да прилагат в управленската си практика, както и да прилагат техники за управление на емоционалната интелигентност. За такъв инструмент се приема коучинга.

Изборьт на коучинга като управленски инструмент, който трябва да се интегрира в практиката на мениджърите се аргументира с това, че чрез него резултатно и трайно могат да се решават редица проблеми, които съпътстват работата по изпълнението на различни организационни цели. Нещо повече - коучингът генерира и мултиплицира синергични ефекти, подпомага процесите по създаване на професионално пригодни служители и не на последно място - може да се използва за повишаване на емоционалната интелигентност на всички кадри в организацията (ръководители и сътрудници).

Целта на настоящата разработка е да се проследи научната дискусия относно приложния характер на коучинга и емоционалната интелигентност като част от уменията и личността на мениджъра-лидер. На тази основа да се идентифицират и систематизират мерки и препоръки, чрез които ръководителите могат да повишат ефективността на своето управление. За изпълнение на така формулираната цел са дефинирани следните изследователски задачи:

- Да се изясни същността на емоционалната интелигентност и ролята и при формирането на личността на мениджъра-лидер. 
- Да се систематизират особеностите и границите на приложение на коучинга като управленски инструмент.

- Да се изследват зависимостите между лидерството, коучинга и емоционалната интелигентност в управлението на бизнес организацията.

$\mathrm{He}$ е обект на анализ цялата палитра от теоретични фундаменти за природата на лидерството, еволюцията на лидерските теории и различните модели за оценка и управление на емоционалната интелигентност. Фокусът е поставен върху приложната страна на лидерството и емоционалната интелигентност, и тяхната свързаност с коучинга като управленски инструмент.

\section{1. Лидерство - традиционни разбирания и актуални изисквания}

По отношение на релацията „мениджмънт-ръководство-лидерство“ са проведени множество научни изследвания. Настоящата разработка няма за цел да отново да изследва тази зависимост, а приема за основополагащо следното:

- Ефективното ръководство предполага лидерство. В този смисъл мениджърът трябва да е лидер. Развивайки своите качества на мениджър, той се превръща в лидер. Това е едно от основанията в настоящата разработката термините „мениджър“ и ,лидер“ да се възприемат за синоними.

- В практиката на мениджъра постигането на оптимални резултати е функция на умелото използване както на формалната, така и на неформалната власт. Използването на различни източници за въздействие върху поведението на служителите и екипите е предпоставка за повишаване на успеваемостта на управленското въздействие.

- Динамиката на средата изисква мениджърът непрекъснато да развива и усъвършенства своите професионални качества, знания и умения. В този смисъл аргументирано може да се предположи, че мениджърът учи непрекъснато, за да отговори на актуалните потребности на бизнеса за резултатност и ефективност на управлението.

- Приема се за по-значима релацията „лидер - последовател“, отколкото „рьководител - подчинен“. Пьрвата се приема за резултат от сътрудничество, коопериране и доверие, а втората е характерна за формалните отношения, които заради своя принудителен характер, могат да предизвикат междуличностни конфликти и други деструктивни ефекти.

В съответствие с целта и задачите на настоящата разработка интерес представлява моделът на лидерство основано на компетенциите, разработен от Саймън Купър ${ }^{1}$. Според автора на този модел способностите или компетенциите на служителите могат да се систематизират в четири групи, а реакцията на лидера ще зависи от това, в коя група е „попаднал“ съответния служител. (Таблица 1)

Таблица 1. Лидерско поведение според концепцията „лидерство основано на компетенциите“

\begin{tabular}{|c|c|c|c|}
\hline № & Ниво на компетентност & Поведение на & Поведение на лидера \\
\hline 1 & Никакви компетенции & $\begin{array}{l}\text { Липсва разбиране на } \\
\text { задачата, липсва } \\
\text { знание и умения за } \\
\text { нейното изпълнение. }\end{array}$ & $\begin{array}{ll}\text { Дава инструкции, } \\
\text { оказва помощ за } \\
\text { справяне със задачата. } \\
\text { (инструкция) }\end{array}$ \\
\hline
\end{tabular}

${ }^{1}$ Kupar, S. (2011) Brilyantniyat lider. Sofiya: IK „Amat-Ah“. 


\section{ИЗВЕСТИЯ НА СЬЮЗА НА УЧЕНИТЕ - ВАРНА}

\begin{tabular}{|c|c|c|c|}
\hline 2 & Частично компетентен & $\begin{array}{l}\text { Знае какво трябва да } \\
\text { направи, но } \\
\text { неуверен в своите } \\
\text { способности. }\end{array}$ & $\begin{array}{l}\text { Проверява процеса на } \\
\text { изпълнение на } \\
\text { задачата, дава обратна } \\
\text { връзка, за да насьрчи } \\
\text { напредъка. Може да } \\
\text { използва различни } \\
\text { управленски подходи, } \\
\text { включително коучинг. } \\
\text { (надзиравана } \\
\text { практика) }\end{array}$ \\
\hline 3 & Най-общо компетентен & $\begin{array}{l}\text { Служителят разбира } \\
\text { задачата и се справя } \\
\text { добре с нейното } \\
\text { изпълнение, но ако тя } \\
\text { се усложни, той ще } \\
\text { изпита затруднения. }\end{array}$ & 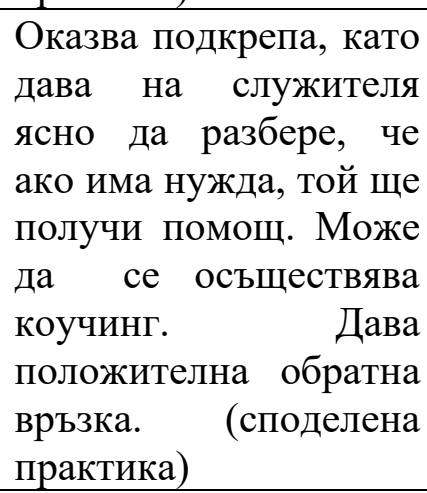 \\
\hline 4 & Напълно компетентен & $\begin{array}{l}\text { Служителят } \quad \frac{r}{\text { има }} \\
\text { практика и опит за } \\
\text { справяне със задачата, } \\
\text { дори и ако тя се } \\
\text { усложни. }\end{array}$ & $\begin{array}{l}\text { Осъществява } \\
\text { мониторинг. Може да } \\
\text { се осъществява } \\
\text { коучинг. } \\
\text { (овластяване) } \\
\end{array}$ \\
\hline
\end{tabular}

Според автора на този модел компетенциите на служителите могат да се оценят с оценки от 1 до 4 и в зависимост от установените нива на компетентност, да се определи поведението на лидера. Модельт съчетава в себе си различни административни и социалнопсихологически въздействия, включително обучение и коучинг, посредством които лидерът може да постига резултати при осъществяване на служебните си задължения.

В така предложения модел фокусът е поставен върху развиването на способностите, които са в основата на постигане на положителни резултати. Различното ниво на компетентност изисква различна лидерска подкрепа и намеса, което е предпоставка за формиране на твърдението, че лидерът трябва да умее да идентифицира качествата и уменията на своите служители, да ги оценява по отношение на поставяната задача и да предприема действия, с които при необходимост, да променя техните компетенции.

Интерес представлява и виждането на Паоло Руджери ${ }^{2}$ за поведението на мениджьралидер в организацията. Според него промяната в поведението на служителите трябва да започне с промяна в поведението на лидера, лидерьт трябва да се научни да критикува конструктивно, да умее да изказва похвала и да умее да вдъхновява своите служители за изпълнение на поставените задачи, да създава среда, в която неговите сътрудници да се чувстват ангажирани и съпричастни, да подхожда с разбиране и съпричастност.

В друг свой труд същият автор ${ }^{3}$ допълва към качествата на лидера уважението, чувството за отговорност и способността на лидера да анализира ситуацията, търсейки причини за нея и в собственото си поведение.

\footnotetext{
${ }^{2}$ Rudzheri, P. (2014) Novite lideri. Sofiya: Dzhey Ey Em Dzhi EOOD.

${ }^{3}$ Rudzheri, P. (2019) Desette pravila na uspeha. Sofiya: Dzhey Ey Em Dzhi EOOD.
} 
Впечатление прави и виждането на Маккъргоу и Бейли ${ }^{4}$ за поведението на лидера в бизнес организацията. Според тях лидерьт е:

- иницииращ и провокиращ;

- гостоприемен и канещ;

- създаващ пространство за работа, мислене, взаимодействие;

- очертаващ граници (прагове) и условия за напредък и развитие;

- създаващ среда за свързване и създаване на синергия (свързване с другите, свързване на другите, всичко е свързано);

- участващ в процесите, дейностите и събитията като равен.

Коментирайки поведението на лидера в бизнес организацията, както и неговите качества във фокуса на внимание попада емоционална интелигентност и нейната значимост при постигането на ефективно лидерство.

Концепцията за емоционалната интелигентност се свързва с името на Даниъл Голман $^{5}$. Тя може да се представи като съвкупност от специфични знания и умения, с помощта на които личността/ лидерьт успешно може да се справя с избора и контрола върху своите емоции, с разбирането и управляването на емоциите на тези, с които общува, а като допълнителен ефект - и да има положително влияние върху личния си успех и този на другите.

Лидерите, с висока емоционална интелигентност според Голман притежават следните ключови характеристики: (Таблица 2)

Таблица 2. Характеристики на лидера според разбирането на Даниъл Голман за емоционална интелигентност

\begin{tabular}{|c|c|c|}
\hline № & Компетенции и умения на лидера & $\begin{array}{c}\text { Компоненти на емоционалната } \\
\text { интелигентност }\end{array}$ \\
\hline 1 & $\begin{array}{l}\text { Самоконтрол }^{6} \text {. Техники за повишаване } \\
\text { на самоконтрола са рефлексия }{ }^{7} \text {, } \\
\text { избягване на отрицателни канотации и } \\
\text { самообвинения, репетиция. }\end{array}$ & $\begin{array}{l}\text { Самоосъзнаване - самоувереност, } \\
\text { реално и емоционално самосъзнание. }\end{array}$ \\
\hline 2 & Самоуважение. & $\begin{array}{l}\text { Саморегулация или самоуправление - } \\
\text { доверие, добросъвестност, емоционален } \\
\text { контрол, инициативност, адаптивност, } \\
\text { оптимизъм, } \\
\text { постижения. }\end{array}$ \\
\hline 3 & Умения за сдружаване и работа в екип. & $\begin{array}{l}\text { Мотивация - предимно вътрешната } \\
\text { мотивация на лидера да заявява, } \\
\text { отстоява и преследва целите си. }\end{array}$ \\
\hline 4 & Емпатия. $^{8}$ & $\begin{array}{l}\text { Социални умения - отзивчивост, } \\
\text { организационна ангажираност. }\end{array}$ \\
\hline 5 & Аналитично мислене. & Ориентация към високи резултати и \\
\hline
\end{tabular}

\footnotetext{
${ }^{4}$ Makkargou, M., Beyli, H. (2017) Gostopriemno liderstvo. Sofiya: Iztok Zapad.

${ }^{5}$ Golman, D. (2011) Emotsionalnata inteligentnost. Sofiya: Iztok-Zapad.

${ }^{6}$ Под самоконтрол се разбира способността да се запазва спокойствие и самообладание при стресови ситуации, въздържане от вземане на необмислени решения, контрол върху неподходящи емоционални реакции в дадена ситуация и др.

7 Рефлексията като психологическа категория предполага самоанализ на вътрешното състояние на личността. Приема се, че обикновено емоционалните реакции са резултат от две емоции - страх и желание.

8 Умението да се съпреживее дадена ситуация или събитие от гледна точка на друг участник. Умението да се разбере емоцията на другите участници в ситуацията или събитието и да се избере поведение, съответно (подходящо) на тези емоции.
} 


\begin{tabular}{|c|c|c|}
\hline & & успехи. \\
\hline 6 & Концептуално мислене. & $\begin{array}{l}\text { Разбиране на средата и организационна } \\
\text { осъзнатост. }\end{array}$ \\
\hline 7 & $\begin{array}{l}\text { Желание за учене, както и умение за } \\
\text { анализиране на системата, от която } \\
\text { лидера е част. Стремеж към } \\
\text { непрекъснато повишаване на знанията и } \\
\text { уменията, в резултат на осъзнаването, че } \\
\text { средата се променя непрекъснато и това } \\
\text { е предпоставка за непрекъснато тьрсене } \\
\text { на ново знание. }\end{array}$ & $\begin{array}{l}\text { Взаимоотношения } \text { и } \\
\text { управление - сяхното } \\
\text { осъществяване на промени, въздействие } \\
\text { и управление на конфликти, } \\
\text { подпомагане работата на останалите, } \\
\text { сътрудничество, работа в екип. }\end{array}$ \\
\hline
\end{tabular}

Според Робърт Ууд и Хари Толи интелектьт никога не е достатъчен за постигане на оптимален резултат на работното място, тъй като много от проблемите са по същество от емоционален характер и те неминуемо влияят върху качеството на вземаните решения и демонстрираните поведения. Способността за справяне с проблемни личности е резултат от умението да се управляват собствените емоции, да се оценява мнението на другите, за да почувства и предвиди как биха реагирали те на направените предложения, както и да има способност за общуване с другите служители в организацията. Всичко това според тях може да се нарича „емоционална интелигентност“.

В допълнение следва да се отбележи, че може да се възприеме едно по-широко разбиране за интелект, в което освен обичайното разбиране за интелигентност ${ }^{10}$, се прибави и способността да се идентифицират и управляват собствените и тези на другите емоции, т.е. емоционалната интелигентност.

Емоционалната интелигентност може да се тълкува и като комплексна цялост от поведения, способности или компетентности, убеждения и ценности, която помага на човека успешно да реализира визията и мисията си, ако му се даде този избор. ${ }^{11}$ Тази дефиниция дава друг аспект на емоционалната интелигентност, а именно способността да се използват емоциите и контрола върху тях (лични и на околните), за да се постигат определени предварително заявени по някакъв начин резултати.

Емоционалната интелигентност предполага личността (лидерът) да разбира как, защо и кога емоциите имат влияние върху мисленето и поведението на човека. Това умение е предпоставка за управление на собствените и тези на другите емоционални състояния. ${ }^{12}$

Майер и Саловей ${ }^{13}$ сьщо се занимават с изследвания на спецификите на емоционалната интелигентност. Според тях емоционалната интелигентност е резултат от:

- Способността да се възприема и демонстрира емоция. В този смисъл може да се разпознае способността да се осъществяват перцепция, интеракция и емпатия, т.е. способността да се осъществява анализ, диагностика и реакция спрямо идентифицираната емоция.

- Способността емоцията да се използва за стартиране на мисловен процес, с който да се аргументира някакво целенасочено поведение от лидера и/ или служителя.

\footnotetext{
${ }^{9}$ Uud, R, Toli, H. (2007) Profesionalni testove za emotsionalna inteligentnost. Sofiya: Lokus.

10 Интелигентността е вродена или придобита способност за анализ и синтез на различна информация, мисловен процес, основан на съждения на база знания и емпиричен опит.

${ }^{11}$ Merlevede, P., Bridu, D., Vandam, R. (2005) 7 stapki kam emotsionalna inteligentnost. Sofiya: Klasika i stil.

12 За повече информация виж: Gercheva-Nestorova, G., Nedyalkova, Yo. (2019) Prilozheniya na psihologiyata $v$ menidzhmanta. Varna: VSU „Ch. Hrabar“.

${ }^{13}$ Mayer, J. D., Salovey, P., Caruso, D. Models of emotional intelligence. In R. J. Sternberg (Ed.), Handbook of intelligence, Cambridge University Press, 2000, pp. 396-420.
} 
- Способността да се осъществява контрол върху изпитваните емоции - тези на самия лидер или тези, които е идентифицирал у тези, с които общува.

Фърнам и Петридес ${ }^{14}$ имат следното разбиране за емоционалната интелигентност според тях емоционалната интелигентност е личностна черта, т.е. емоционалната интелигентност е присъща характеристика на личността, която включва:

- възприемане, изразяване, управление и регулиране на емоциите (собствени и чужди);

- емпатия;

- самоуважение;

- подходящи за целите взаимоотношения с околните;

- умения за управление на стреса;

- ниска степен на импулсивност;

- адаптивност;

- настойчивост и асертивност (способност да се отстоява аргументирано и адекватно собственото мнение);

- оптимизъм и щастие;

- автомотивация и желание за успех и развитие;

- социални умения (съзнание).

Така определените аспекти на емоционалната интелигентност, според авторите, могат да се систематизират и обобщят в следните основни категории:

- Самоконтрол - има се предвид равнище на импулсивност и умения за регулиране на емоциите, както и способността за управление на стреса.

- Благополучие - включва самоуважение, оптимизъм, щастие.

- Емоционалност - начин на възприемане на събития, факти, личности, начин на изразяване, способност за управление на емоциите и взаимоотношенията, емпатия.

- Общителност - в състава и влизат асертивност, социално съзнание (умения), управление на емоциите.

Направеният преглед на научната дискусия относно поведението и ролята на лидера в организацията и особеностите на емоционалната интелигентност като същностна негова черта, позволяват формирането на следните авторови разбирания:

- Посочените в изложението на този параграф текстове позволяват формирането на извод, че ефективното управление и лидерство включва в себе си като характеристика и условие за успех и емоционалната интелигентност.

- Може да се направи и следното твърдение - предпоставка за ефективно лидерство в съвременните условия за правене на бизнес е наличието на висока емоционална интелигентност у мениджъра. Основание за това твърдение е факта, че значителна част от ключовите му характеристики попадат и в съдържателния обхват на емоционалната интелигентност.

- Аргументирано се предполага, че в резултат на еволюцията на разбирането за ефективно лидерство, емоционалната интелигентност се добавя към набора от качества, които лидера трябва да притежава. В този смисъл връзката между ефективното лидерство и емоционалната интелигентност е правопропорционална.

\footnotetext{
${ }^{14}$ Petrides, K. V., Furnham, A. (2000) On the dimensional structure of emotional intelligence. London: Personality and Individual Differences, 29, pp. 313-320, [Online] Available from: http://www.psychometriclab.com/adminsdata/files/PAID\%20(2000)\%20-\%20T_EI.pdf, [Accessed 09/10/2020].
} 
- В своята практика ефективните лидери, развивайки своята емоционална интелигентност и професионална пригодност трябва да усвояват и различни управленски инструменти, посредством които да влияят на своите служители така, че и те да развиват своя потенциал и професионална пригодност. В настоящата разработка се възприема твърдението, че коучингът е именно такъв инструмент и е добре той да се превърне в част от практиката на мениджъралидер.

\section{2. Коучинг в практиката на лидера}

През последните няколко години приложението на коучига в управлението на бизнес организациите е обект на анализ от много учени и изследователи.

Смята се, че чрез него могат да се решават редица проблеми, които с традиционните управленски техники се решават по-трудно или по-неефективно. В този смисъл авторът на настоящата разработка, приема, че освен като самостоятелна професия, респективно - като длъжност, която може да съществува в организацията, коучингът следва да бъде умение, което лидерът трябва да притежава и да е част от неговата практика. Това е и част от защитаваната авторова теза.

Чрез коучингът, според автора, успешно могат да се решават проблеми свързани с:

- делегирането на права;

- вземането на решение;

- решаване на междуличностни конфликти от различно естество;

- развитие на екипи;

- мотивиране на служители;

- разкриване на потенциала на служители;

- кариерно планиране и развитие;

- развитие на потенциала на мениджърите.

Така идентифицираните области на приложение на коучинга като управленски инструмент в практиката на лидера, позволяват формирането на следните базови твърдения:

- Коучингът успешно може да допълни практиката на лидера и да повиши управленския му потенциал.

- Коучингът създава индивидуални и синергични ефекти на различни нива, като резултат от използването му за решаването на различни проблеми.

- Коучингът създава мултиплициращи се ефекти там, където се прилага, в свързани с мястото на приложението му структурни звена и в организацията като цяло.

- Използването на коучинг в практиката на лидера влияе положително върху неговия авторитет.

Усвояването на коучинг технологията и използването и като управленски инструмент е предпоставка за:

- изграждане на доверие между ръководител и ръководен, което може да остане трайно във времето и да се превърне в предпоставка за дългосрочно и ползотворно сътрудничество на работното място;

- разкриване на осъзнати и неосъзнати възможности и способности на коуча (лидера) и коучвания (служителя);

- учене в движение - коучваният осъзнава своя истински потенциал, коучът научава нови неща за ръководената от него организация от начина, по който коучвания я представя, както и нови неща за самия коучван, за средата в която работи, за проблема, който се решава в момента; 
- изграждане на доверие между рьководител и ръководен, в този смисъл усвояването на коучинг технологията и използването и като управленски инструмент е предпоставка за превръщането на мениджъра коуч в лидер;

- развиване на комуникативните умения на коуча и по-конкретно - уменията за питане, слушане и наблюдаване;

- развиване на емоционалната интелигентност на коуча, тъй като добрия коучинг изисква способност на коуча да овладява емоциите си и да прилага коучинг технологията абсолютно безпристрастно. Твърдението е вярно и в обратната посока - високата емоционална интелигентност е фактор, който може да подпомогне за по-лесното усвояване на коучинг технологията.

Важно е да се отбележи, че прилагането на коучинг в практиката на лидера може да крие и рискове. Като по-значими могат да се посочат:

- Неспособност или невъзможност да се изгради доверие между коуч и коучван.

- Злоупотреба или неправомерно използване на информация, акумулирана по време на коучинга.

- Възможност за субективно влияние от страна на коуча при решаването на различни проблеми по време на коучинга.

- Страх от страна на коучвания, че време на коучинг сесиите може да каже нещо, което да го злепостави, дискредитира или да повлияе негативно при бъдеща негова атестация.

Така очертаните зависимости между коучинга като управленски инструмент и неговото приложение в практиката на мениджъра лидер позволяват формирането и на следното твърдение:

Еволюцията на управленската практика изисква усвояването и прилагането на непопулярни за досегашното трудово ежедневие на мениджърите техники и подходи. За такъв инструмент се приема коучинга, който със своята специфика позволява въздействие върху хора и екипи по един нов и нетрадиционен за досегашната практика начин, който може да генерира различни ползи, синергични ефекти и мултиплициращи се резултати. Коучингът допълва практиката на мениджъра лидер и е предпоставка за повишаване на неговата професионална пригодност.

\section{3. Релацията „лидерство - коучинг - емоционална интелигентност на лидера“}

Въз основа на предложените до момента факти за ролята на емоционалната интелигентност, лидерството и коучинга е разработена примерна концептуална рамка, с която може да се преследва постигането на ефективно лидерство (Фигура 1). В нея са обособени 3 основни роли на лидера:

- на учещ;

- на коуч;

- на лидер.

Изборът на тези роли е резултат от систематизираните факти, резултат от прегледа на научната дискусия по коментираните в разработката въпроси, както и от синтеза на авторовите съждения относно съдържанието на ефективното лидерство.

Защитава се позицията, че лидерьт в своята практика непрекъснато трябва да усъвършенства своите знания, умения и компетенции. Това е основанието да се предложи ролята на учещ. Лидерът, в своята практика, ежедневно се сблъсква с нови ситуации, които по естествен начин го поставят именно в тази роля. Правейки това, той трябва да усвоява нови техники и подходи за вземане на решение и за въздействие върху тези, с които работи. С това се аргументира и заявената като необходима роля, ролята на лидера-коуч. Усвоявайки коучинг технологията и придобивайки умението да прилага коучинг в своята практика, лидерьт обогатява управленския си инструментариум. 
По този начин се променя съвкупността от знания и умения, които той притежава, както и неговата емоционална интелигентност. В резултат на поведението му като лидер и коуч, промени настьпват и в набора от знания и умения, както и в равнището на емоционална интелигентност на служителите в организацията.

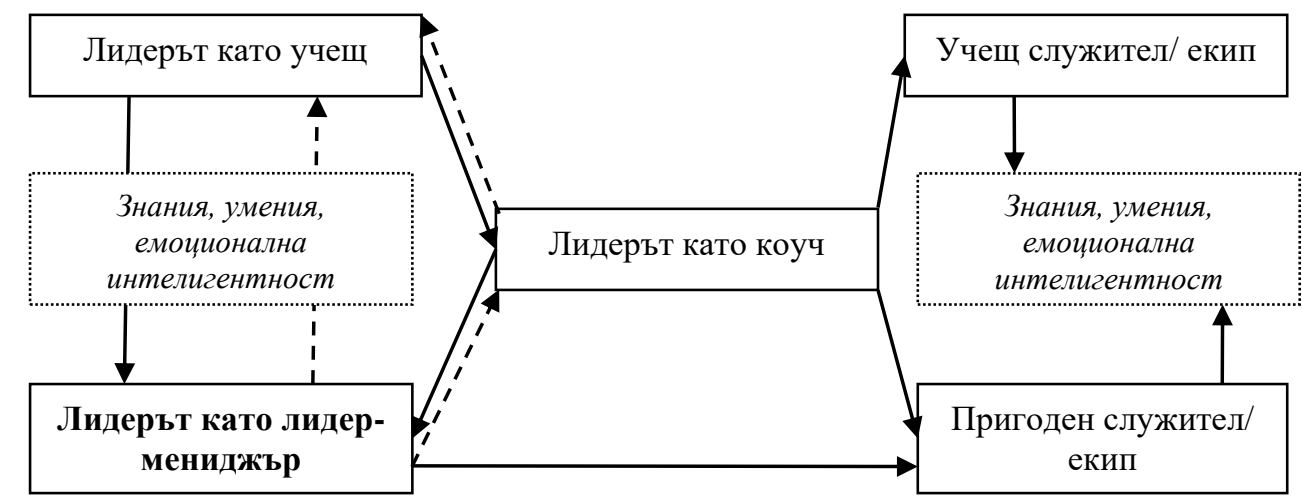

Фигура 1. Концептуална рамка за ефективно лидерство

В предложената концептуална рамка са посочени потенциалните зависимости и релации в практиката и поведението на лидера, както и трансформацията, която настъпва в резултат на придобиването на нови знания и умения и осъществяването на коучинг.

\section{Заключение}

В резултат на изложение факти и твърдения в настоящата разработка, могат да се направят следните изводи и обобщения:

Първо: Ефективното лидерство предполага наличието на специфични знания, умения и компетенции, които се придобиват, развиват и прилагат ежедневно в практиката на лидера, а разработената концептуална рамка за постигане на ефективно лидерство може да се използва за изграждане и развитие на лидерските качества.

Второ: Високата емоционална интелигентност е предпоставка за лидерство. Установено е, че при изграждането на образа на ефективния лидер качествата, с които той се описва, включват и такива, които са характерни за личност, която притежава висока емоционална интелигентност.

Трето: Коучингът е управленски инструмент, който ефективният лидер трябва да притежава. Умението за осъществяване на коучинг в своята практика е предпоставка мениджърьт да се справя по-резултатно с разрешаването на различни проблеми. Освен това той може да си прави самокоучинг или самият той да бъде коучван.

Четвърто: Усвояването на коучинг и възприемането му като част от практиката на мениджъра, както и целенасоченото развитие на емоционалната интелигентност изисква ревизиране и актуализиране на възприетия за традиционен набор от качества, който трябва да притежава добрият ръководител.

Пето: Не бива да се абсолютизира значението на коучинга и на емоционалната интелигентност при създаването и развитието на лидерите. Безспорно, наличието на умения за осъществяване на коучинг, както и високата емоционална интелигентност на мениджъра са предпоставка за превръщането му в лидер, но те могат да се разглеждат само като необходими, но не и като достатъчни условия за ефективно лидерство. Съдържателният обхват на ефективното лидерство включва много повече качества, знания и умения, които мениджъра-лидер трябва да притежава.

Литература

1. Bradberi, T., Griyvs, Dzh. (2019) Emotsionalna inteligentnost 2.0, Sofiya: Iztok Zapad. 
2. Gercheva-Nestorova, G., Nedyalkova, Yo. (2019) Prilozheniya na psihologiyata $v$ menidzhmanta. Varna: VSU „Ch. Hrabar“.

3. Golman, D. (2011) Emotsionalnata inteligentnost. Sofiya: Iztok-Zapad.

4. Ivanov, D. (2014) Liderstvo. Sofiya: Siela.

5. Ivanova, Sn. (2017) Emotsionalnata inteligentnost i upravlenie na povedenieto na choveka. Eastern Academic Journal, Issue 4, pp.17-32, [Online] Available from: https://www.eacadjournal.org/bg/article-17-4-3.html, [Accessed 07/10/2020]

6. Klatarbak, D. (2012) Kouching na ekipi i rabotni grupi. Sofiya: NLP Balgariya.

7. Kolins, Dzh. (2003) Patyat kam velichieto. Sofiya: Klasika i stil.

8. Kostadinova, I. (2013) Definirane na kategoriite „emotsionalna i sotsialna inteligentnost” za tselite na praktikoprilozhni izsledvaniya, Naushni trudove na Rusenskiya universitet, tom 52, seriya 5.1, pp. 84-89

9. Kupar, S. (2011) Brilyantniyat lider. Sofiya: IK „Amat-Ah“.

10. Landsberg, M. (2006). Kouching. Moskva: Eksmo.

11. Makgoff, K. (2015) Iskusstvo upravlyat'. Moskva: Mann, Ivanov i Ferber.

12. Makkargou, M., Beyli, H. (2017) Gostopriemno liderstvo. Sofiya: Iztok Zapad.

13. Maksuel, Dzh. (2017) 5-te niva na liderstvo. Sofiya: Anhira.

14. Mayer, J. D., Salovey, P., Caruso, D. Models of emotional intelligence. In R. J. Sternberg (Ed.), Handbook of intelligence, Cambridge University Press, 2000, pp. 396-420.

15. Merlevede, P., Bridu, D., Vandam, R. (2005) 7 stapki kam emotsionalna inteligentnost. Sofiya: Klasika i stil.

16. Noyes, R. (2011) Izkustvoto da rakovodish sebe si. Sofiya: Persey.

17. O‘Konar, Dzh. i Leydzhis, A. (2012). Kouching s NLP. Sofiya: Kolibri.

18. Petrides, K. V., Furnham, A. (2000) On the dimensional structure of emotional intelligence. London: Personality and Individual Differences, 29, pp. 313-320, [Online] Available from: http://www.psychometriclab.com/adminsdata/files/PAID\%20(2000)\%20-\%20T_EI.pdf, [Accessed 09/10/2020]

19. Rudzheri, P. (2019) Desette pravila na uspeha. Sofiya: Dzhey Ey Em Dzhi EOOD.

20. Rudzheri, P. (2014) Novite lideri. Sofiya: Dzhey Ey Em Dzhi EOOD.

21. Salovey, P., Mayer, J., (1990) Emotional intelligence, Imagination, Cognition and Personality, 9, Baywood Pub1ishing Co. 1990, pp. 185-211. [Online] Available from: http://ei.yale.edu/wpcontent/uploads/2014/06/pub153_SaloveyMayerICP1990_OCR.pdf, [Accessed 12/10/2020]

22. Stak, E. (2006). Kouching na predpriyatii. Moskva: Institut konsul'tirovaniya i sistemnykh resheniy.

23. Uud, R, Toli, H. (2007) Profesionalni testove za emotsionalna inteligentnost. Sofiya: Lokus.

24. Uitmor, Dzh. (2012). Kouching za visoki postizheniya. Sofiya: NLP Balgariya.

25. Uitmor, Dzh. (2000). Coaching - novyy stil' menedzhmenta i upravleniya personalom. Moskva: Finansy i statistika. 